\title{
Editorial
}

\section{Different Perspectives of Homeopathic Research Seal the Year 2021}

In this last 2021 issue, five articles are published concerning different aspects of homeopathic research, from a review of clinical studies on Polycystic Ovarian Syndrome and the therapeutic potential of homeopathy to treat these cases (Dewan et al., 2021) to a detailed systematic analysis of nanoparticles suspended in homeopathic preparations (Van Wassenhoven et al., 2021). In between, some interesting reports can also be found, as a case report about the successful treatment of a rectum prolapse in a kitten in a period of a few days with no need of surgery (Makker and Arora, 2021); an opinion article (update article) reported the necessity to develop clinical studies on homeoprofilaxy of Covid-19 in which the key aspects of immunocompetence could be evaluated, such as the serum levels of cytokines, mainly those related to the systemic inflammatory syndrome such as IL-6, and of neutralizing IgG and IgM (Patil, 2021); and an original article about the physicochemical properties of a Covid-19 nosode, in which different patterns were described using spectrophotometric methods, resulting in an electronic signature of each potency (Kumar Singh et al., 2021).

Enjoy the reading and happy 2022 for us all!

IJHDR Editorial Team

\section{References}

Patil AD. Int J High Dilution Res. 2021; 20(4): $02-05$.

https://doi.org/10.51910/ijhdr.v20i4.1098

Makker and Arora. Int J High Dilution Res. 2021; 20(4): 06-10.

https://doi.org/10.51910/ijhdr.v20i4.1109

Van Wassenhoven et al. Int J High Dilution Res. 2021; 20 (4): 11-28.

https://doi.org/10.51910/ijhdr.v20i4.1113

Dewan et al. Int J High Dilution Res. 2021;20(4):29-45.

https://doi.org/10.51910/ijhdr.V20i4.1126.

Kumar Singh et al. Int J High Dilution Res. 2021; 20(4): 46-59.

https://doi.org/10.51910/ijhdr.v20i4.1099

(C) International Journal of High Dilution Research.

Not for commercial purposes. 